\title{
CHEMICAL COMPOSITION AND ANTIFUNGAL ACTIVITY OF HEDERA HELIX LEAF ETHANOLIC EXTRACT
}

\author{
Oana Roșca-Casian, ${ }^{1}$ * Cristina Mircea, ${ }^{2 *}$ Laurian Vlase, ${ }^{3}$ \\ Ana-Maria Gheldiu, ${ }^{3}$ Delia Tania Teuca ${ }^{2}$ and Marcel PÂRvu ${ }^{2}$ \\ 1“A. Borza” Botanical Garden, "Babeş-Bolyai" University, \\ 42 Republicii Street, 400015 Cluj-Napoca, Romania \\ ${ }^{2}$ Department of Biology, Faculty of Biology and Geology, "Babeş-Bolyai" University, \\ 42 Republicii Street, 400015 Cluj-Napoca, Romania \\ ${ }^{3}$ Department of Pharmaceutical Technology and Biopharmaceutics, Faculty of Pharmacy, \\ "Iuliu Haţieganu" University of Medicine and Pharmacy, 12 Ion Creangă Street, \\ 400010 Cluj-Napoca, Romania
}

(Received: November 29, 2016; accepted: January 30, 2017

\begin{abstract}
The 50\% ethanol extract obtained from Hedera helix leaves was investigated regarding the presence and quantity of polyphenols, sterols and in vitro antifungal activity against phytopathogenic fungi. The chemical analysis revealed the presence of rutin, quercetin and kaempferol in the non-hydrolysed sample and quercetin and kaempferol in the hydrolysed sample and stigmasterol in the ivy leaf extract (nonhydrolysed sample). The antifungal activity against phytopathogenic fungi (Aspergillus niger, Botrytis cinerea, B. tulipae, Fusarium oxysporum f. sp. tulipae, Penicillium gladioli, and Sclerotinia sclerotiorum) was assessed using an agar dilution assay. The results are expressed as the minimum inhibitory concentration $(\mathrm{MIC}=10-14 \%)$ and were compared to a synthetic antifungal drug - fluconazole (MIC $=8-30 \%)$. This report presents the first screening of the antifungal activity of the ivy leaf extract on these plant pathogenic fungi species, aiming to use the ivy leaf extract for controlling different diseases of vegetables and ornamental plants, in addition to human disorders.
\end{abstract}

Keywords: Antifungal - Hedera helix - phytopathogenic fungi - polyphenols - sterols

\section{INTRODUCTION}

Hedera helix (ivy) is an evergreen woody liana (Araliaceae family) native to most of Europe and Western Asia. The leaves are alternate, evergreen with an accentuated polymorphism; thus, the juvenile leaves are palmate with 3-5 lobes, while the adult ones are cordate, rhomboid to ovate-lanceolate. The flowers produced from summer until late autumn are small, greenish-yellow and come in umbels of 3-5 cm in diameter. The fruits are small black berries that ripen in winter. It is a popular ornamental plant in many countries [13].

In addition to its ornamental value, ivy is used as a medicinal plant. The ivy leaf has been used since ancient times (Dioscorides and Hippocrates), but the phytotherapeutical books of the 16th century would describe very different indications. Steinmetz, in 1961, presumed that although the plant is decidedly poisonous (in large

*Corresponding authors; e-mail addresses: casioana@gmail.com; mircea.i.cristina@gmail.com 
doses death can occur by respiratory paralysis), the leaves and berries administered in safe doses have some good uses in therapy [37].

The aim of the present research was to investigate the antifungal properties of the ivy leaf extract against plant pathogenic fungi and to identify and quantify the phenolic compounds and sterols from the leaf extract that are believed to be responsible for the antifungal activity.

\section{MATERIALS AND METHODS}

\section{Plant material}

Hedera helix was collected from the Alexandru Borza Botanical Garden of ClujNapoca $\left(46^{\circ} 45^{\prime} 36^{\prime \prime} \mathrm{N} ; 23^{\circ} 35^{\prime} 13^{\prime \prime} \mathrm{E}\right.$ ), and a voucher specimen (CL 664210) is deposited at the Herbarium of Babes-Bolyai University, Cluj-Napoca, Romania.

\section{Plant extract preparation}

The plant extract was prepared by a cold repercolation method at room temperature for 3 days [30] by using small fragments $(0.5-1 \mathrm{~cm})$ of ivy leaves, which were extracted with 50\% ethanol (Merck, Bucuresti, Romania) in the Mycology Laboratory of Babes-Bolyai University, Cluj-Napoca, Romania. The Drug Extract Ratio (DER) was $1: 1$.

\section{Preparation of fungal colonies}

The plant pathogenic fungi chosen for the experiment cause important losses to vegetable and ornamental crops and have never been used to test the antifungal properties of ivy leaf extract. For this purpose, Aspergillus niger was isolated from onion bulbs, Botrytis cinerea from rose flowers, B. tulipae and Fusarium oxysporum f. sp. tulipae from tulip flowers and bulbs, respectively, Penicillium gladioli from gladiolus corms, and Sclerotinia sclerotiorum from carrot roots. All the fungal species were identified in the Mycology Laboratory (Babes-Bolyai University, Cluj-Napoca, Romania), by Dr. M. Parvu. The colonies were obtained in Petri dishes on Czapek-agar medium (BD Difco, Budapest, Hungary) by inoculation in the central point with a spore suspension $\left(1 \times 10^{5}\right.$ conidia $\left.\times \mathrm{mL}^{-1}\right)$ and an incubation at $22{ }^{\circ} \mathrm{C}$ for 5 days.

\section{Determination of antifungal activity}

The antifungal activity of the Hedera helix leaf extract, expressed as MIC, was assessed by the agar dilution assay and was compared to the antimycotic drug fluconazole $\left(2 \mathrm{mg} \times \mathrm{mL}^{-1}, \mathrm{Krka}\right.$, Novo Mesto, Slovenia) and a control (nutritive medium 
and ethanol). The results were interpreted by calculating the percentage of mycelial growth inhibition $(P)$ at each concentration, by using the formula $P=(C-T) \times 100 / C$, where $C$ is the diameter of the control colony and $T$ is the diameter of the treated colony [21].

\section{Analysis of polyphenols from the ivy leaf extract}

\section{Apparatus and chromatographic conditions}

The experiment was carried out using an Agilent 1100 HPLC Series system equipped with an autosampler G1311A. For the separation, a reversed-phase Zorbax SB-C18 analytical column $(100 \times 3.0 \mathrm{~mm}$ i.d., $3.5 \mu \mathrm{m}$ particle $)$ was used. The column was operated at $48{ }^{\circ} \mathrm{C}$ in a G1316A oven. For the gradient elution, a degasser G1322A and quaternary gradient pump G1311A were employed. The detection of all of the compounds was performed at 330 and $370 \mathrm{~nm}$ using G1316A diode array detector system, and the chromatographic data were processed with the Chemstation software (Agilent, USA). The mobile phase was prepared from methanol and acetic acid $0.1 \%$ $\left(\mathrm{V} \times \mathrm{V}^{-1}\right)$. The elution began with a linear gradient (started at 5 to $42 \%$ methanol) for the first $35 \mathrm{~min}$, followed by an isocratic elution with $42 \%$ methanol for the next $3 \mathrm{~min}$

The flow rate was $1 \mathrm{~mL} \times \mathrm{min}^{-1}$, and the injection volume was $5 \mu \mathrm{L}$. All of the solvents were filtered through $0.5 \mu \mathrm{m}$ filters (Sartorius) and we degassed in an ultrasonic bath. For the liquid chromatography (LC) electrospray ionization (ESI) mass spectrometry (MS) analysis, an Agilent Ion Trap 1100 SL instrument was used. The MS was equipped with a Turbo-Ionspray (electrospray ionization) interface in negative ion mode. The ESI settings were as follows: negative ionization; ion source temperature: $350{ }^{\circ} \mathrm{C}$; gas: nitrogen at $12 \mathrm{~L} \times \mathrm{min}^{-1}$; and nebulizer: $70 \mathrm{psi}$ $[11,22,24,35]$.

\section{Chemicals}

Standards: chlorogenic acid, $p$-coumaric acid, caffeic acid, rutin, apigenin, quercitrin, isoquercitrin, hyperoside, kaempferol, quercetin, myricetol and fisetin were purchased from Sigma (Germany); ferulic acid, sinapic acid, gentisic acid, patuletin and luteolin from Roth (Germany); and cichoric acid and caftaric acid from Dalton (USA). Methanol of HPLC analytical-grade and hydrochloric acid of analytical-grade were purchased from Merck (Germany). Methanolic stock solutions $\left(1 \mathrm{mg} \times \mathrm{mL}^{-1}\right)$ of the above standards were prepared, stored at $4{ }^{\circ} \mathrm{C}$, and were protected from daylight. They were appropriately diluted with double-distilled water before being used as working solutions. 


\section{Identification and quantitative determination of the polyphenols}

A high-performance liquid chromatographic (HPLC) method was developed for the determination of phenolic compounds from ivy extract [35]. The simultaneous analysis of different classes of polyphenols was performed by a single column pass, and the separation of all of the examined compounds was carried out in $35 \mathrm{~min}$. To obtain more accurate data on the flavonoid glycosides and aglycones concentrations and to estimate the nature of the hydrolysed compounds, each sample was analysed once before and after the acid hydrolysis. The concentrations of the identified polyphenolic compounds were determined in all of the analysed samples before and after the acid hydrolysis. Two millilitres of the extract was treated with $2 \mathrm{~mL}$ of $2 \mathrm{M}$ hydrochloric acid and $0.2 \mathrm{~mL}$ of the ascorbic acid solution $100 \mathrm{mg} \times \mathrm{mL}^{-1}$, and the mixtures were heated at $80{ }^{\circ} \mathrm{C}$ in a water bath for $30 \mathrm{~min}$, ultrasonicated for $15 \mathrm{~min}$ and heated for another $30 \mathrm{~min}$ at $80^{\circ} \mathrm{C}$. During the heating, $1 \mathrm{~mL}$ methanol was added to the extraction mixture every $10 \mathrm{~min}$ in order to ensure the permanent presence of methanol. The mixtures were centrifuged at $4000 \mathrm{rpm}$, and the solutions were diluted with distilled water in a $10 \mathrm{~mL}$ volumetric flask and were filtered through a $0.45 \mathrm{~mm}$ filter before injection.

\section{Identification and quantitative determination of sterols}

The LC-MS technique was also used to analyse the sterols from the ivy leaf extract. Thus, a Zorbax SB-C18 reversed-phase analytical column $(100 \times 3.0 \mathrm{~mm}$ i.d., $3.5 \mu \mathrm{m}$ particle) operated at $40{ }^{\circ} \mathrm{C}$ was used. The separation was achieved using a mobile phase consisting of 10:90 (V/V) methanol and acetonitrile with a flow rate of $1 \mathrm{~mL} /$ min and an injection volume of $5 \mu \mathrm{L}$. Mass spectrometry analysis was performed on an Agilent Ion Trap 1100 VL mass spectrometer with atmospheric pressure chemical ionization (APCI) interface. The instrument was operated in a positive ion mode. The gas temperature (nitrogen) was $325^{\circ} \mathrm{C}$ at a flow rate of $7 \mathrm{~L} / \mathrm{min}$, nebulizer pressure $60 \mathrm{psi}$ and capillary voltage $-4000 \mathrm{~V}$. Three standards were used for the quantitative analysis, namely $\beta$-sitosterol, stigmasterol, and cholesterol.

\section{Statistical analysis}

The statistical analyses of the experimental data were performed in the $\mathrm{R}$ environment (version 2.14.1) using a one-way ANOVA and the post hoc Tukey HSD test for the significance of differences between treatments. $P$ values $\leq 0.05$ were considered to be statistically significant. The correlation analysis was performed by the Pearson test. 


\section{RESULTS}

The analysis of polyphenols from the Hedera helix leaf extract revealed the presence of rutin, quercetin and kaempferol in the non-hydrolysed sample (Fig. 1) and quercetin and kaempferol in the hydrolysed sample (Fig. 2). The quantification of the polyphenols in the ivy leaf extract displayed a quantity of $120.655 \pm 6.032 \mu \mathrm{g} \times \mathrm{mL}^{-1}$ rutin, $1.550 \pm 0.069 \mu \mathrm{g} \times \mathrm{mL}^{-1}$ quercetin, and $1.278 \pm 0.063 \mu \mathrm{g} \times \mathrm{mL}^{-1} \mathrm{kaempferol}$ in the non-hydrolysed sample, and $24.068 \pm 1.203 \mu \mathrm{g} \times \mathrm{mL}^{-1}$ quercetin, $7.513 \pm 0.338$ $\mu \mathrm{g} \times \mathrm{mL}^{-1}$ kaempferol in the hydrolysed sample, whereas the analysed sample of the ivy leaf extract contained $0.373 \pm 0.018 \mathrm{ng} \times \mathrm{mL}^{-1}$ stigmasterol.

Taking into consideration some of the most frequent diseases of vegetables and ornamentals, 6 phytopathogenic fungi (Aspergillus niger, Botrytis cinerea, B. tulipae, Fusarium oxysporum f. sp. tulipae, Penicillium gladioli, and Sclerotinia sclerotiorum) were selected for testing the antifungal properties of the Hedera helix leaf extract. The extract inhibited the germination and growth of the plant pathogenic fungi in a concentration-dependent manner. The minimum inhibitory concentration (MIC) varied between $10 \%$ and $14 \%(P \leq 0.05)$ for the leaf extract compared to $8 \%$ and $30 \%(P \leq 0.05)$ for fluconazole (Table 1$)$. These results are comparable with those obtained in our previous study for the ivy flower extract $(\mathrm{MIC}=8-12 \%)$ and fruit

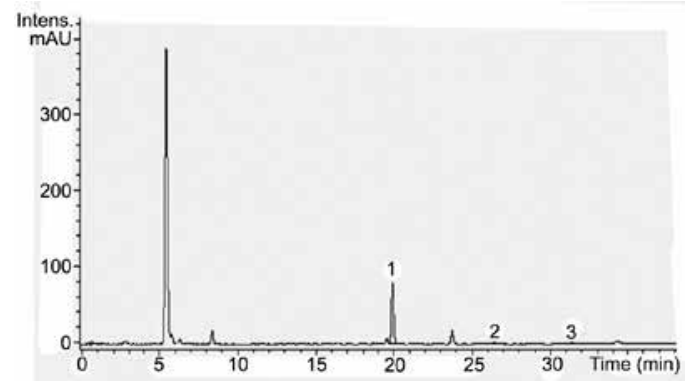

Fig. 1. Chromatogram of the polyphenols from the non-hydrolysed sample of the Hedera helix leaf extract. The peaks are marked: " 1 " rutin; " 2 " quercetin; " 3 " kaempferol

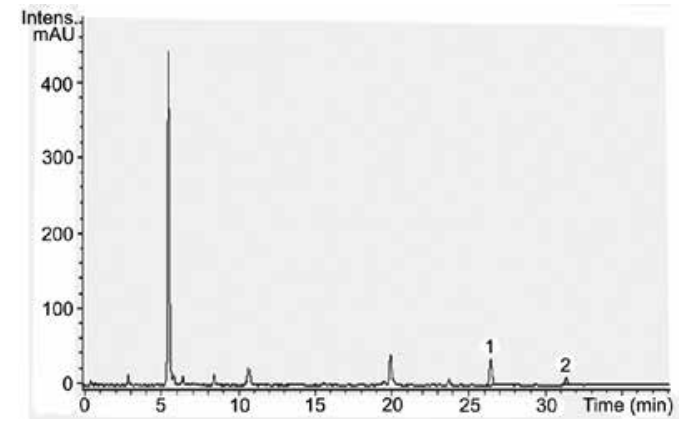

Fig. 2. Chromatogram of the polyphenols from the hydrolysed sample of the Hedera helix leaf extract. The peaks are marked: "1" quercetin; "2" kaempferol 
Table 1

In vitro effect of the Hedera helix leaf extract

\begin{tabular}{|c|c|c|c|c|c|c|c|}
\hline \multirow{2}{*}{$\begin{array}{l}\text { Phyto- } \\
\text { pathogenic } \\
\text { fungus }\end{array}$} & \multirow{2}{*}{$\begin{array}{c}\text { Hedera helix } \\
\text { leaf extract } \\
(1: 1) \\
\text { concentration } \\
(\%)\end{array}$} & \multirow{2}{*}{$\begin{array}{c}\text { Colony's } \\
\text { diameter } \\
(\mathrm{mm})\end{array}$} & \multirow{2}{*}{$\begin{array}{c}\mathrm{Pa} \\
(\%)\end{array}$} & \multicolumn{2}{|c|}{$\begin{array}{l}\text { Fluconazole } \\
\left(2 \mathrm{mg} \times \mathrm{mL}^{-1}\right) \\
\text { concentration }\end{array}$} & \multirow{2}{*}{$\begin{array}{l}\text { Colony's } \\
\text { diameter } \\
(\mathrm{mm})\end{array}$} & \multirow{2}{*}{$\begin{array}{l}\mathrm{P}^{\mathrm{b}} \\
(\%)\end{array}$} \\
\hline & & & & $(\%)$ & $\left(\mathrm{mg} \times \mathrm{mL}^{-1}\right)$ & & \\
\hline \multirow{6}{*}{$\begin{array}{l}\text { Aspergillus } \\
\text { niger }\end{array}$} & $\mathrm{C}$ & 22 & 0 & \multicolumn{2}{|r|}{$\mathrm{C}$} & 22 & 0 \\
\hline & 6 & 18 & $18.18 \pm 0.81$ & 10 & 0.2 & 11 & $54.13 \pm 0.50$ \\
\hline & 8 & 15 & $31.81 \pm 0.50$ & 20 & 0.4 & 7 & $68.18 \pm 0.50$ \\
\hline & 10 & 8 & $63.63 \pm 0.57$ & 25 & 0.5 & 3 & $86.36 \pm 0.57$ \\
\hline & 12 & 2 & $90.90 \pm 0.57$ & 30 & 0.6 & 0 & 100 \\
\hline & 14 & 0 & 100 & & & & \\
\hline \multirow{5}{*}{$\begin{array}{l}\text { Botrytis } \\
\text { cinerea }\end{array}$} & $\mathrm{C}$ & 65 & 0 & \multicolumn{2}{|r|}{ C } & 65 & 0 \\
\hline & 3 & 44 & $32.30 \pm 0.50$ & 2 & 0.04 & 40 & $38.46 \pm 0.50$ \\
\hline & 6 & 11 & $83.07 \pm 0.81$ & 6 & 0.12 & 20 & $69.23 \pm 0.95$ \\
\hline & 8 & 4 & $93.84 \pm 0.95$ & 10 & 0.20 & 3 & $95.38 \pm 0.50$ \\
\hline & 10 & 0 & 100 & 12 & 0.24 & 0 & 100 \\
\hline \multirow{5}{*}{$\begin{array}{l}\text { Botrytis } \\
\text { tulipae }\end{array}$} & $\mathrm{C}$ & 62 & 0 & \multicolumn{2}{|r|}{$\mathrm{C}$} & 62 & 0 \\
\hline & 3 & 41 & $33.87 \pm 0.50$ & 2 & 0.04 & 50 & $19.35 \pm 0.50$ \\
\hline & 6 & 10 & $83.87 \pm 0.50$ & 6 & 0.12 & 24 & $61.29 \pm 0.81$ \\
\hline & 8 & 3 & $95.16 \pm 0.57$ & 10 & 0.20 & 3 & $95.16 \pm 0.50$ \\
\hline & 10 & 0 & 100 & 12 & 0.24 & 0 & 100 \\
\hline \multirow{6}{*}{$\begin{array}{l}\text { Fusarium } \\
\text { oxysporum } \\
\text { f. sp. tulipae }\end{array}$} & $\mathrm{C}$ & 32 & 0 & \multicolumn{2}{|r|}{$\mathrm{C}$} & 32 & 0 \\
\hline & 3 & 29 & $9.37 \pm 0.57$ & 2 & 0.04 & 20 & $37.5 \pm 0.50$ \\
\hline & 6 & 17 & $46.87 \pm 0.50$ & 6 & 0.12 & 8 & $75 \pm 0.50$ \\
\hline & 8 & 12 & $62.5 \pm 0.50$ & 8 & 0.16 & 2 & $93.75 \pm 0.57$ \\
\hline & 10 & 4 & $87.5 \pm 0.81$ & 10 & 0.20 & 0 & 100 \\
\hline & 12 & 0 & 100 & & & & \\
\hline \multirow{6}{*}{$\begin{array}{l}\text { Penicillium } \\
\text { gladioli }\end{array}$} & $\mathrm{C}$ & 15 & 0 & \multicolumn{2}{|r|}{ C } & 15 & 0 \\
\hline & 3 & 11 & $26.66 \pm 0.50$ & 10 & 0.2 & 11 & $26.66 \pm 0.50$ \\
\hline & 6 & 7 & $53.33 \pm 0.81$ & 16 & 0.32 & 9 & $40 \pm 0.50$ \\
\hline & 8 & 3 & $80 \pm 0.57$ & 20 & 0.4 & 6 & $60 \pm 0.50$ \\
\hline & 10 & 0 & 100 & 25 & 0.5 & 3 & $80 \pm 0.50$ \\
\hline & & & & 30 & 0.6 & 0 & 100 \\
\hline \multirow{5}{*}{$\begin{array}{l}\text { Sclerotinia } \\
\text { sclerotiorum }\end{array}$} & $\mathrm{C}$ & 64 & 0 & \multicolumn{2}{|r|}{$\mathrm{C}$} & 64 & 0 \\
\hline & 3 & 31 & $51.56 \pm 0.50$ & 2 & 0.04 & 30 & $53.12 \pm 0.50$ \\
\hline & 6 & 15 & $76.56 \pm 0.57$ & 4 & 0.08 & 15 & $76.56 \pm 0.50$ \\
\hline & 8 & 3 & $95.31 \pm 0.81$ & 6 & 0.12 & 4 & $93.75 \pm 0.57$ \\
\hline & 10 & 0 & 100 & 8 & 0.16 & 0 & 100 \\
\hline
\end{tabular}

Legend: athe effect of the Hedera helix leaf extract; bthe effect of fluconazole; $\mathrm{P}=$ mycelial growth inhibition; $\mathrm{C}=\operatorname{control}(50 \%$ aq. EtOH); results are the mean $\pm \mathrm{SD}$ of 4 replicates. 

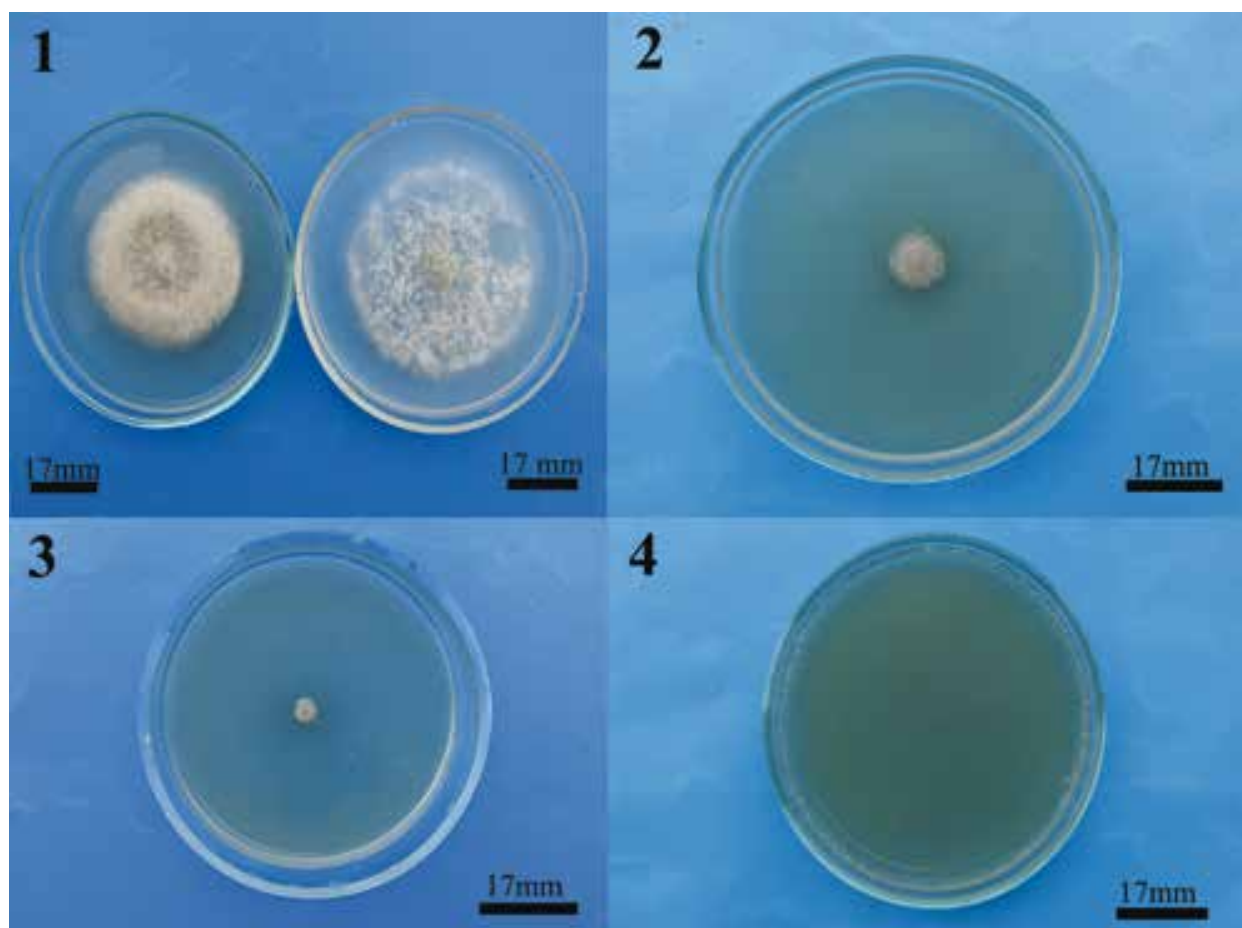

Fig. 3. The antifungal activity of the Hedera helix leaf extract on the germination and growth of the Botrytis cinerea fungus: 1 - control colony (left) and colony treated with 3\% ivy leaf extract (right), 5 days after inoculation; $\mathbf{2}$ - colony treated with $6 \%$ ivy leaf extract, 5 days after inoculation; $\mathbf{3}$ - colony treated with $8 \%$ ivy leaf extract, 5 days after inoculation; 4 - colony treated with $10 \%$ ivy leaf extract, 5 days after inoculation (total inhibition)

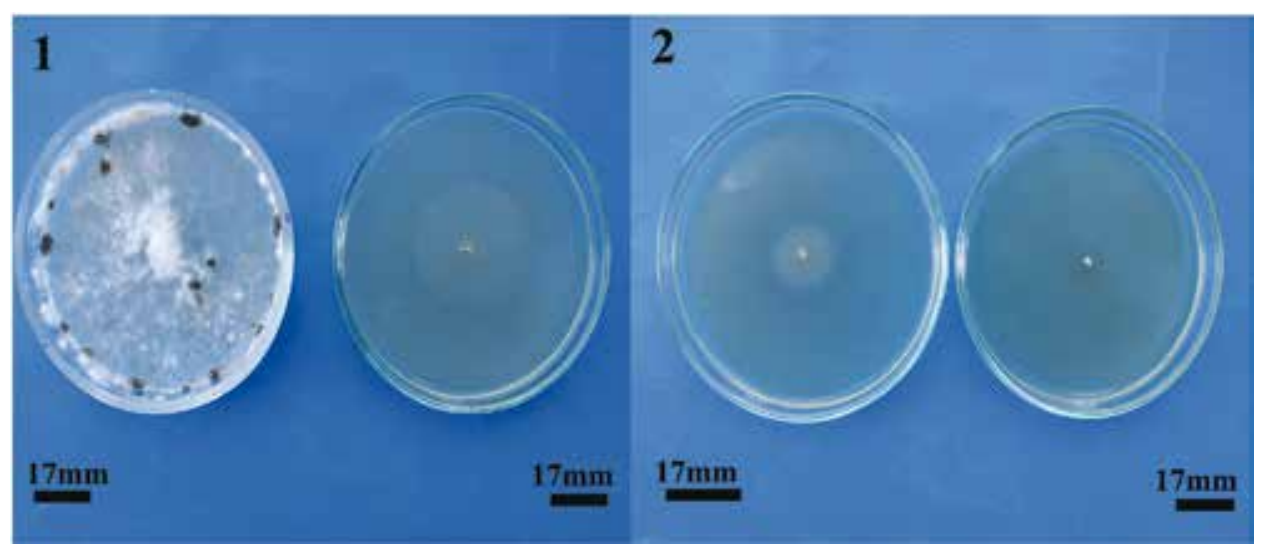

Fig. 4. The antifungal activity of the Hedera helix leaf extract on the germination and growth of the Sclerotinia sclerotiorum fungus: $\mathbf{1}$ - control colony, 14 days from inoculation (left) and colony treated with $2 \%$ ivy leaf extract, 5 days after inoculation (right); 2 - Colony treated with $6 \%$ ivy leaf extract (left) and colony treated with $10 \%$ ivy leaf extract (right), 5 days after inoculation (total inhibition) 
extract (MIC $=10-14 \%)$ [23]. These findings suggest that ivy flowers contain principles with higher antifungal activities and might be more efficient in treating plant mycoses.

Ivy leaf extract inhibited, in a similar manner, the fungi causing grey mould (Botrytis cinerea - Fig. 3, B. tulipae), blue mould (Penicillium gladioli) and white rot (Sclerotinia sclerotiorum - Fig. 4) of plants. The MIC for all of these fungi was $10 \%$. Less of an inhibitory effect was recorded in the case of Fusarium oxysporum f. sp. tulipae, with a MIC of $12 \%$. The most resistant of all of the selected fungi was Aspergillus niger, with a MIC of $14 \%$. At any rate, the obtained results are better than those for fluconazole (Table 1), which makes the ivy leaf extract a promising biocontrol agent for plant pathogenic fungi.

\section{DISCUSSION}

The antifungal activity of plant extracts is due to chemical constituents, such as alkaloids, polyphenols, saponins, sterols and essential oils [31]. Therefore, it is important to identify and quantify such bioactive compounds using adequate methods [3].

The phytochemical screening of Hedera helix indicated the presence of different classes of secondary metabolites, such as alkaloids, terpenoids, saponins and tannins. These compounds vary in type in different parts of the plant and are dependent on the type of the solvent used for the extraction. The chloroform and methanolic extracts revealed the presence of alkaloids, while terpenoids, saponins, and tannins were present in the $n$-hexane, chloroform, ethyl acetate and methanol extracts, respectively [33]. In the methylene chloride extract, from the leaves of Hedera helix, the following active components were found: $\beta$-amyrin; stigmasterol and hexadecanoic acid [20].

Using a new solid-liquid extraction technique highlighted the presence of active ingredients in the aqueous leaf extract of Hedera helix. Thus, flavonoids, proteins, amino acids and small amounts of triterpene saponins were recorded. In the extract, the flavonoids rutin, quercetin, kaempferol, and apigenin were identified, and the amino acids asparagine, glycine, isoleucine, leucine, phenylalanine, proline, tyrosine, and valine were identified by means of chromatographic methods [10].

Numerous studies have investigated the bioactive compounds of Hedera helix. Such studies used different methods to identify the compounds. Thus, triterpene saponins, such as hederasaponins $\mathrm{E}(1), \mathrm{F}(2), \mathrm{H}(7)$ and $\mathrm{I}(8)$ and cauloside $\mathrm{F}$, were isolated from the leaves of Hedera helix and were characterised by chemical and spectroscopic methods [9]. The saponins hederacoside $\mathrm{C}$ and $\alpha$-hederin, from different ivy leaf extracts, were detected using reversed-phase high-HPLC [6].

A thorough investigation of the phenolic constituents from the dry extract of Hedera helix revealed the presence of rutin, kaempferol 3-O-rutinoside, quercetin 3-O-glucoside, kaempferol 3-O-glucoside, quercetin, kaempferol, chlorogenic acid, neochlorogenic acid, 4,5- and 3,5-O-dicaffeoyl-quinic acids, as well as rosmarinic, caffeic, and protocatechuic acids. These compounds were isolated and identified by spectroscopic methods [32]. 
Furthermore, data from the literature mention the presence of emetine alkaloid in the ivy plant. Emetine is a natural product alkaloid found in several plant species. Its structure was elucidated, and its biological properties were studied. Thus, the antiviral, anticancer, antiparasitic and contraceptive activities were assigned. The major problem discouraging the medicinal use of this alkaloid is represented by cardiotoxicity and cytotoxicity, but these are dose-dependent [1]. Emetine alkaloid was separated for the first time from the alcoholic extract of the four varieties of Hedera helix growing in Egypt. The presence of the alkaloid was investigated by applying IR, UV, NMR and MS analyses [17]. Another innovative, sensitive and accurate method for the isolation and quantification of emetine alkaloid is the RP-HPLC [15].

Even if most of the studies elucidate the chemical composition of plant extracts, we believe that it is equally important to quantify the bioactive substances, because they might be very different depending on the plant organ, the solvent, and the method used for extraction.

The goal after identifying and isolating biologically active compounds from plants is to study them as possible curing agents. These kinds of studies are related especially to the therapeutic properties of the bioactive compounds, which are mainly used to treat human disorders. Such studies showed the anti-inflammatory effect of ivy, specifically the saponins extracted from the leaves of Hedera helix [7] and the anti-inflammatory and antiarthritic effects of the ethanolic extract of Hedera helix, which were found to be comparable to that of diclofenac [26]. Additionally, the methanolic extract of Hedera helix leaves and the saponins (hederacolchiside-E and -F) have dose-dependent analgesic and anti-inflammatory activities [12, 19].

A number of studies regarding ivy properties have demonstrated its benefits in respiratory diseases. Such studies confirmed that ivy leaf extract, in the form of syrup and in cough drops, is an effective and safe treatment of cough in children [28], in acute bronchitis therapy [4], and for acute upper respiratory tract infections, in general [16]. The traditional use of ivy for medicinal purposes is confirmed by its secretolytic, expectorant, and bronchospasmolytic effects, mainly due to the triterpene saponins, which are the main ingredients and are pharmacologically the most important substances from the ivy leaf extracts [29]. Moreoever, the Hedera helix extract was reported to have antitumour [25] and antimutagenic [34] effects, antioxidant properties due to the saponins ( $\alpha$-hederin and hederasaponin-C) [14], hypoglycemic activity [36], antileishmanial [18] and antihelmintic [8] properties.

Studies regarding the antimicrobial properties of the Hedera helix extracts are incomparably fewer. Such studies mention that the aqueous extract of Hedera helix has antibacterial, antimycobacterial and antifungal activities [5]. The ethyl acetate and methanol extracts were active against two strains of Gram-negative bacteria (Escherichia coli, Klebsiella pneumoniae) and three strains of Gram-positive bacteria (Staphylococcus aureus, S. epidermidis, Bacillus subtilis) at concentration of 22 $\mathrm{mg} \times \mathrm{mL}^{-1}[33]$.

In addition to its therapeutic properties for human disorders, there are a few studies related to the antibacterial and antifungal activity of the ivy extract against plant pathogenic agents. Interesting results were obtained when testing the antibacterial 
effect of the Hedera helix extract against Erwinia amylovora. The ivy extract caused a pronounced increase in peroxidase and chitinase activity and induced the activation of defence genes, leading to the accumulation of structural and biochemical activities at strategic sites, which can be associated with induction of resistance against fireblight [2]. More specifically, the ethanolic extract of Hedera helix exhibited a high degree of antifungal activity against late blight (Phytophthora infestans) of tomato and downy mildew (Pseudoperonospora cubensis) of cucumber [27].

Previous studies attest the antifungal properties of ivy extract against plant pathogenic fungi, while our results contribute the data in the literature on this topic with useful information regarding the possibility of being able to control plant pathogenic fungi that cause important and frequent diseases to vegetables and ornamental plants. Further studies should consider the assessment of the specific bioactive compound with the highest antifungal activity.

\section{CONCLUSIONS}

The ivy leaf ethanolic extract exhibited antifungal activity against the tested phytopathogenic fungi (Aspergillus niger, Botrytis cinerea, B. tulipae, Fusarium oxysporum f. sp. tulipae, Penicillium gladioli and Sclerotinia sclerotiorum) in a dosedependent manner with an MIC of $10 \%$ to $14 \%$. The results were comparable to those obtained for a synthetic drug (fluconazole), which makes ivy leaf extract a costeffective and a potent herbal control agent for the treatment of plant diseases, such as grey mould, plant wilt and white rot. We believe that the antifungal activity is highly due to the polyphenols (rutin, quercetin, kaempferol) and the sterol (stigmasterol) that were detected in considerable amounts in the ivy leaf extract. Also, the role of the saponins with proven antifungal activity cannot be overlooked.

\section{REFERENCES}

1. Akinboye, E. S., Bakare, O. (2011) Biological activities of emetine. Open Nat. Prod. J. 4, 8-15.

2. Baysal, O., Zeller, W. (2004) Extract of Hedera helix induces resistance on apple rootstock M26 similar to Acibenzolar-S-methyl against fire blight (Erwinia amylovora). Physiol. Mol. Plant P. 65, 305-315.

3. Buchwald, W., Mordalski, R., Kucharski, W. A., Gryszczyńska, A., Adamczak, A. (2015) Effect of fertilization on roseroot (Rhodiola rosea L.) yield and content of active compounds. Acta Sci. Pol. Hortorum Cultus 14, 109-121.

4. Cwientzek, U., Ottillinger, B., Arenberger, P. (2011) Acute bronchitis therapy with ivy leaves extracts in a two-arm study. A double-blind, randomised study vs. another ivy leaves extract. Phytomedicine $18,1105-1109$

5. Deliorman Orhan, D., Özçelik, B., Hoşbaş, S., Vural, M. (2012) Assessment of antioxidant, antibacterial, antimycobacterial, and antifungal activities of some plants used as folk remedies in Turkey against dermatophytes and yeast-like fungi. Turk. J. Biol. 36, 672-686.

6. Demirci, B., Goppel, M., Demirci, F., Franz, G. (2004) HPLC profiling and quantification of active principles in leaves of Hedera helix L. Pharmazie 59, 770-774. 
7. Dumitriu, B., Olariu, L., Nita, R., Zglimbea, L., Rosoiu, N. (2013) Vascular anti-inflammatory effects of natural compounds from Aesculus hippocastanum and Hedera helix. Rom. Biotech. Lett. 18, 7963-7974.

8. Eguale, T., Tilahun, G., Debella, A., Feleke, A., Makonnen, E. (2007) Haemonchus contortus: In vitro and in vivo anthelmintic activity of aqueous and hydro-alcoholic extracts of Hedera helix. Exp. Parasitol. 116, 340-345.

9. Elias, R., Diaz Lanza, A. M., Vidal-Ollivier, E., Balansard, G., Faure, R., Babadjamian, A. (1991) Triterpenoid saponins from the leaves of Hedera helix. J. Nat. Prod. 54, 98-103.

10. Ferrara, L., Naviglio, D., Faralli, S. (2013) Identification of active principles of Hedera helix L. in aqueous extracts. J. Phytochem. Photon. 114, 170-175.

11. Fodorea, C. S., Vlase, L., Leucuţa, S. E., Tămaş, M. (2005) Phytochemical study on some polyphenols of Geranium pyrenaicum. Chem. Nat. Compd. 41, 400-403.

12. Gepdiremen, A., Mshvildadze, V., Süleyman, H., Elias, R. (2005) Acute anti-inflammatory activity of four saponins isolated from ivy: Alpha-hederin, hederasaponin-C, hederacolchiside-E and hederacolchiside-F in carrageenan-induced rat paw edema. Phytomedicine 12, 440-444.

13. Gruenwald, J., Brendler, T., Jaenicke, C. (2000) PDR for Herbal Medicines. Medical Economics Company, Montvale.

14. Gülçin, I., Mshvildadze, V., Gepdiremen, A., Elias, R. (2004) Antioxidant activity of saponins isolated from ivy: $\alpha$-Hederin, hederasaponin-C, hederacolchiside-E and hederacolchiside-F. Planta Med. $70,561-563$.

15. Han, G. R., Wang, Y. F., Feng, S. H., Jia, Y. X. (2013) Simultaneous determination of cephaeline and emetine in ipecac and its preparations using RP-HPLC. Chinese Herb. Med. 5, 286-291.

16. Lutsenko, Y., Bylka, W., Matlawska, I., Darmohray, R. (2010) Hedera helix as a medicinal plant. Herba Pol. 56, 83-96.

17. Mahran, G. H., Hilal, S. H., El-Alfy, T. S. (1975) The isolation and characterization of emetine alkaloid from Hedera helix. Planta Med. 27, 127-132.

18. Majester-Savornin, B., Elias, R., Diaz-Lanza, A. M., Balansard, G., Gasquet, M., Delmas, F. (1991) Saponins of the ivy plant, Hedera helix, and their leishmanicidic activity. Planta Med. 57, 260-262.

19. Mandade, R. J., Choudhuri, A., Mashirkar, V., Sakarkar, D. (2010) Analgesic and anti-inflammatory activities of Hedera helix leaf extract. Pharmacie Globale (Int. J. Comprehen. Pharm.), 1, 1-3.

20. Medeiros, J. R., Medeiros, H., Mascarenhas, C., Davin, L. B., Lewis, N. G. (2002) Bioactive components of Hedera helix. Arquipél., Life Mar. Sci. 19A, 27-32.

21. Nidiry, E. S. J., Babu, C. S. B. (2005) Antifungal activity of tuberose absolute and some of its constituents. Phytother. Res. 19, 447-449.

22. Pârvu, M., Vlase, L., Fodorpataki, L., Pârvu, O., Roşca-Casian, O., Bartha, C., Barbu-Tudoran, L., Pârvu, A. E. (2013) Chemical composition of celandine (Chelidonium majus L.) extract and its effects on Botrytis tulipae (Lib.) Lind fungus and the tulip. Not. Bot. Hort. Agrobot. Cluj-Napoca, 41, 414426.

23. Pârvu, M., Vlase, L., Pârvu, A.-E., Roşca-Casian, O., Gheldiu, A.-M., Pârvu, O. (2015) Phenolic compounds and antifungal activity of Hedera helix L. (ivy) flowers and fruits. Not. Bot. Hort. Agrobot. Cluj-Napoca 43, 53-58.

24. Peev, C. I., Vlase, L., Antal, D. S., Dehelean, C. A., Szabadai, Z. (2007) Determination of some polyphenolic compounds in buds of Alnus and Corylus species by HPLC. Chem. Nat. Compd. 43, 259262

25. Rai, A. (2011) The effects of alcoholic Hedera helix plant extract on Ehrlich ascitic tumour cells in vitro and its antitumour activities in vivo. Int. J. Pharm. Sci. Rev. Res. 11, 47-50.

26. Rai, A. (2013) The antiinflammatory and antiarthritic properties of ethanol extract of Hedera helix. Indian J. Pharm. Sci. 75, 99-102.

27. Röhner, E., Carabet, A., Buchenauer, H. (2004) Effectiveness of plant extracts of Paeonia suffruticosa and Hedera helix against diseases caused by Phytophthora infestans in tomato and Pseudoperonospora cubensis in cucumber. J. Plant Dis. Prot. 111, 83-95. 
28. Schmidt, M., Thomsen, M., Schmidt, U. (2012) Suitability of ivy extract for the treatment of paediatric cough. Phytother. Res. 26, 1942-1947.

29. Stauss-Crabo, M., Atiye, S. (2009) Ivy, a traditionally used medicinal plant in modern phytotherapy (Review). Z. Phytother. 30, 289-291.

30. Sundaram, U., Gurumoorthi, P. (2012) Validation of HPTLC method for quantitative estimation of L-Dopa from Mucuna pruriens. Int. Res. J. Pharm. 3, 300-304.

31. Şesan, T. E., Enache, E., Iacomi, B. M., Oprea, M., Oancea, F., Iacomi, C. (2015) Antifungal activity of some plant extracts against Botrytis cinerea Pers. in the blackcurrant crop (Ribes nigrum L.). Acta Sci. Pol., Hortorum Cultus 14, 29-43.

32. Trute, A., Nahrstedt, A. (1997) Identification and quantitative analysis of phenolic compounds from the dry extract of Hedera helix. Planta Medica 63, 177-179.

33. Uddin, G., Rauf, A., Qaisar, M., Rehman, T. U., Latif, A., Ali, M. (2011) Preliminary phytochemical screening and antimicrobial activity of Hedera helix L. Middle-East J. Sci. Res. 8, 198-202.

34. Villani, P., Orsière, T., Sari-Minodier, I., Bouvenot, G., Botta, A. (2001) Antimutagenic effects of alphahederin in vitro. Ann. Biol. Clin. 59, 285-289.

35. Vlase, L., Pârvu, M., Pârvu, E. A., Toiu, A. (2013) Chemical constituents of three Allium species from Romania. Molecules 18, 114-127.

36. Zafar, I., Mohammad, P., Asadullah Muhammad, I., Bashir, A., Shahida, Z., Saima, G. (2002) Study of the hypoglycemic activity of Hedera helix L. in alloxan-induced diabetic rabbits. J. Med. Sci. 2, 206-208.

37. www.ema.europa.eu. European Medicines Agency. (2012) Assessment report on Hedera helix L. folium. 